\title{
THE FATE OF GLUCOSAMINE HYDROCHLORIDE INJECTED INTRAVENOUSLY IN MAN *
}

\author{
BY
}

\author{
S. WEIDEN $\dagger$ AND I. J. WOOD $\dagger$ \\ From the Clinical Research Unit of the Walter and Eliza Hall Institute of Medical Research and the \\ Royal Melbourne Hospital, Victoria, Australia
}

(RECEIVED FOR PUBLICATION JANUARY 10, 1958)

Glucosamine is known to be a constituent of the numerous mucocomplexes in man. These serve many important functions in the form of intercellular components, cementing substances, lubricants in joint and ocular fluids, and as aids to intestinal motility in the form of mucins of the alimentary tract.

However, apart from a few very incomplete early reports on the fate of glucosamine in biological systems, there is little information available on the metabolism of glucosamine in man. This relative lack of knowledge has inspired the present investigation, namely, the development of an intravenous glucosamine tolerance test. The intravenous rather than the oral route was chosen to eliminate any error due to any breakdown or malabsorption of the compound in the alimentary canal, and because of early reports that oral glucosamine caused diarrhoea.

Most of the information on the metabolism of glucosamine dates back to the earlier part of this century (Offer and Frankel, 1899 ; Fabian, 1899 ; Stolte, 1908). Experiments on human subjects carried out at about that time showed that the excretion of glucosamine into the urine began in the second hour after its ingestion and continued for a long period thereafter. Some conflicting results were obtained at the time.

It was not until 1934 that Kawabe, using organic assay, traced the fate of orally and subcutaneously administered glucosamine hydrochloride in normal adult rabbits and found it to be distributed in the liver, kidney, and stomach mucosa as well as in the small intestine and the pancreas. Recently Boas and Foley (1955) injected glucosamine hydrochloride into rats, and found that $80 \%$ to $90 \%$ disappeared from the blood in 10 minutes. This occurred in the intact animal as well as in one in which the liver or kidney had been excluded from

*Submitted in part by S. Weiden for the degree of Ph.D., University of Melbourne.

+Working with the aid of a grant from the National Health and Medical Research Council of Australia. the general circulation, suggesting that the liver did not play a major role in the metabolism of glucosamine. The glucosamine was distributed mostly in those tissues which are rich in extracellular fluid, but the highest concentration was in the liver. Estimation by Boas and Foley (1955) of the total amount of glucosamine left in the animal and excreta at the end of an hour after an intravenous dose of glucosamine hydrochloride showed that approximately $50 \%$ of the dose had been metabolized. Their claim that only a small fraction of the intravenously administered dose is excreted in the urine does not agree either with earlier findings in animals or with the present investigation in man.

\section{Methods}

A $20 \%$ glucosamine hydrochloride solution was prepared for intravenous injection. The $20 \%$ concentration was the highest possible for a satisfactory solution. The $p \mathrm{H}$ of the solution was 2.2 , and no attempt was made to buffer it. It was stored at $-4^{\circ} \mathrm{C}$. At this acid $p \mathrm{H}$ and low temperature the glucosamine was not broken down. As no information was available on the toxicity of the compound when injected intravenously, preliminary experiments were carried out using rabbits, and the final technique was based on these findings.

The patient fasted from 10 p.m. the previous evening. A fasting sample of blood was taken and divided into two portions, one added to a sodium fluoride-thymol powder, and the other allowed to clot. Then a dose of $\frac{1}{3} \mathrm{~g}$. $/ \mathrm{kg}$. body weight of glucosamine hydrochloride was injected intravenously, taking an average time of 10 minutes.

Clinically the reaction during injection was minimal, the main symptoms being a temporary and slight blurring of vision, a general warmth of the body, and in some instances a "tingling" feeling in the limbs. The pulse and respiration rates showed little or no change.

Blood samples were obtained at $15,30,60,120$, and 180 minutes after the injection. Urine was collected four-hourly for 24 hours. Also, in the first 
intravenous tests a 24-hour sample of urine was collected on the day preceding the test as well as on the day of the test and the following one. A few drops of glacial acetic acid were added to the specimens during collection and the bottles were kept in the refrigerator.

Using the sodium fluoride-thymol specimens, protein-free filtrates were obtained and free hexosamine levels determined. The clotted specimens were centrifuged, the serum taken off hydrolysed, and the total hexosamine present determined (Weiden, 1958). The hexosamine content of the urine was determined before and after hydrolysis.

Determination of Free Hexosamine in Blood.-It is necessary to determine the amount of free hexosamine remaining in the blood during the intravenous glucosamine test. A protein-free filtrate of the blood was prepared according to the method described by Somogyi (1945). The hexosamine content of the filtrate was determined by the method previously described (Weiden, 1958).

Estimation of Hexosamine in Urine.-To determine the hexosamine content of urine, $1 \mathrm{ml}$. of urine was hydrolysed with $1 \mathrm{ml}$. of $4 \mathrm{~N}-\mathrm{HCl}$ for six hours in a boiling water-bath. After cooling, the sample was neutralized with $4 \mathrm{~N}-\mathrm{NaOH}$ to $p \mathrm{H} 6$ using "universal" indicator paper, then diluted with distilled $\mathrm{H}_{2} \mathrm{O}$ to a final volume which depended on the concentration of hexosamine present. In order to determine the final volume, in many instances a trial run had to be carried out. The final volumes varied from 10 to $500 \mathrm{ml}$.

Reports in the literature that it is impossible to determine urinary hexosamine because of interfering chromagens were not substantiated. Interference due to urea, as reported by Lutwak-Mann (1941), was not encountered as the final dilution of the hydrolysate was considerable; this was especially so in the samples obtained immediately following the injection, when, as will be shown later, the greater part of the glucosamine is excreted. In the few instances where an interfering chromagen was obtained. it was due to some medication received by the patient. such as sulphonamides; where possible this treatment was stopped on the day before the test.

\section{Results}

Altogether 32 intravenous glucosamine tolerance tests were carried out on 31 patients, including six with uncomplicated diabetes mellitus, three with liver disease, six suffering from carcinoma (one stomach, two lung, one hepatic ducts, one bronchus with secondaries in the liver, and one colon with secondaries in the liver), four with renal disease, and one each with coronary sclerosis, multiple myeloma, lupus erythematosus, Hodgkin's disease, and Sjögren's disease.

Seven patients with quiescent peptic ulcer were included as controls.

Free Blood Hexosamine Levels after Intravenous Injection of Glucosamine Hydrochloride.-

Free hexosamine could not be detected in the blood of any of the patients before injection of glucosamine hydrochloride.

After injection there was a rise in the free blood hexosamine; the highest value was obtained at 15 minutes and this was followed by a return towards the normal level in the following specimens. The results are given in Table $I$.

The seven patients suffering from quiescent peptic ulcer were considered to be normal controls. The three patients with liver disease were suffering from acute infectious hepatitis, chronic infectious hepatitis, and nutritional hepatitis respectively. All three showed poor liver function tests, a raised serum bilirubin level, positive cephalin flocculation, increased $\gamma$-globulin level, and, in the latter two, a lowered serum albumin and raised alkaline phosphatase level (Wood, Garlick. Motteram, Weiden, Moore, Mackay, and Turner, 1949). In spite of the poor liver function in these patients, the blood hexosamine levels after the intravenous injection of glucosamine hydrochloride showed the same rise and fall encountered in the control patients.

TABLE I

FREE BLOOD HEXOSAMINE LEVELS AFTER THE INTRAVENOUS GLUCOSAMINE TEST

\begin{tabular}{|c|c|c|c|c|c|c|c|c|c|c|c|}
\hline \multirow{2}{*}{\multicolumn{5}{|c|}{ Diagnosis }} & \multirow{3}{*}{$\begin{array}{l}\text { No. of } \\
\text { Cases }\end{array}$} & \multicolumn{6}{|c|}{ Average Excretion and Range of Free Hexosamine (mg.\%) } \\
\hline & & & & & & \multirow{2}{*}{$\mathrm{F}$} & \multicolumn{5}{|c|}{ Time in Minutes after Injection of Glucosamine Hydrochloride } \\
\hline & & & & & & & 15 & 30 & 60 & 120 & 180 \\
\hline $\begin{array}{l}\text { Normal } \ldots \\
\text { Liver disease ... } \\
\text { Diabetes mellitus with } \\
\text { Carcinoma } \\
\text { Renal disease .. } \\
\text { Coronary sclerosis } \\
\text { Multiple myeloma } \\
\text { Hodgkin's disease } \\
\text { Lupus erythematosus } \\
\text { Sjögren's disease }\end{array}$ & $\begin{array}{l}\cdots \\
\text { nor } \\
\cdots \\
\cdots \\
\cdots \\
\cdots\end{array}$ & $\begin{array}{l}\cdots \\
\text { al re } \\
\cdots \\
\cdots \\
\cdots \\
\cdots \\
\cdots\end{array}$ & $\begin{array}{l}\cdots \\
\text { fu } \\
\cdots \\
\cdots \\
\cdots \\
\cdots \\
\cdots\end{array}$ & $\begin{array}{l}\ldots \\
\cdots \\
\text { on } \\
\cdots \\
\cdots \\
\cdots \\
\cdots \\
\cdots\end{array}$ & $\begin{array}{l}7 \\
3 \\
6 \\
6 \\
4 \\
1 \\
1 \\
1 \\
1 \\
1\end{array}$ & $\begin{array}{l}\text { Nil } \\
,, \\
, \\
,, \\
,, \\
,, \\
, \\
,,\end{array}$ & $\begin{array}{c}63(38-82) \\
71(64-81) \\
64(15-81) \\
67(23-84) \\
66(43-79) \\
28 \\
60 \\
66 \\
65 \\
51\end{array}$ & $\begin{array}{c}48(30-70) \\
57(43-71) \\
56(30-64) \\
40(13-50) \\
61(42-73) \\
25 \\
45 \\
56 \\
56 \\
49\end{array}$ & $\begin{array}{c}40(17-54) \\
41(32-50) \\
38(21-60) \\
36(30-41) \\
56(40-63) \\
23 \\
43 \\
37 \\
46 \\
37\end{array}$ & $\begin{array}{c}24(9-36) \\
26(14-34) \\
27(13-38) \\
26(18-37) \\
44(36-53) \\
14 \\
23 \\
25 \\
22 \\
35\end{array}$ & $\begin{array}{c}14(\mathrm{Nil}-21) \\
16(9-21) \\
18(\mathrm{Nil}-29) \\
16(\mathrm{Nil}-33) \\
36(23-46) \\
9 \\
14 \\
20 \\
10 \\
30\end{array}$ \\
\hline
\end{tabular}


The group of six patients with diabetes mellitus were all patients who as yet had received no treatment for their diabetic condition, or in whom the

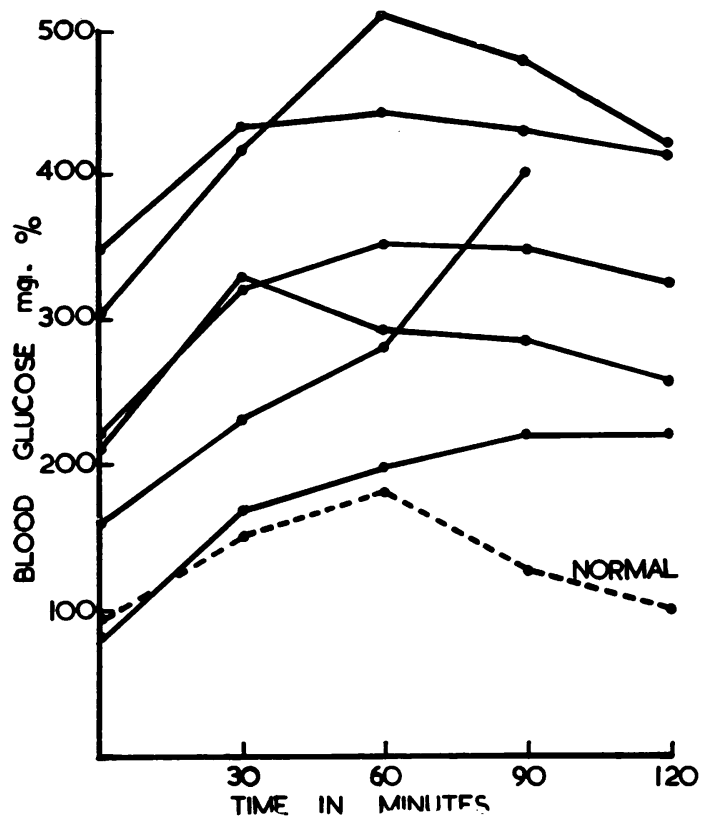

FIG. 1.-Results of the oral glucose tolerance test in the six patients with diabetes mellitus who were also subjected to an intravenous glucosamine tolerance test.

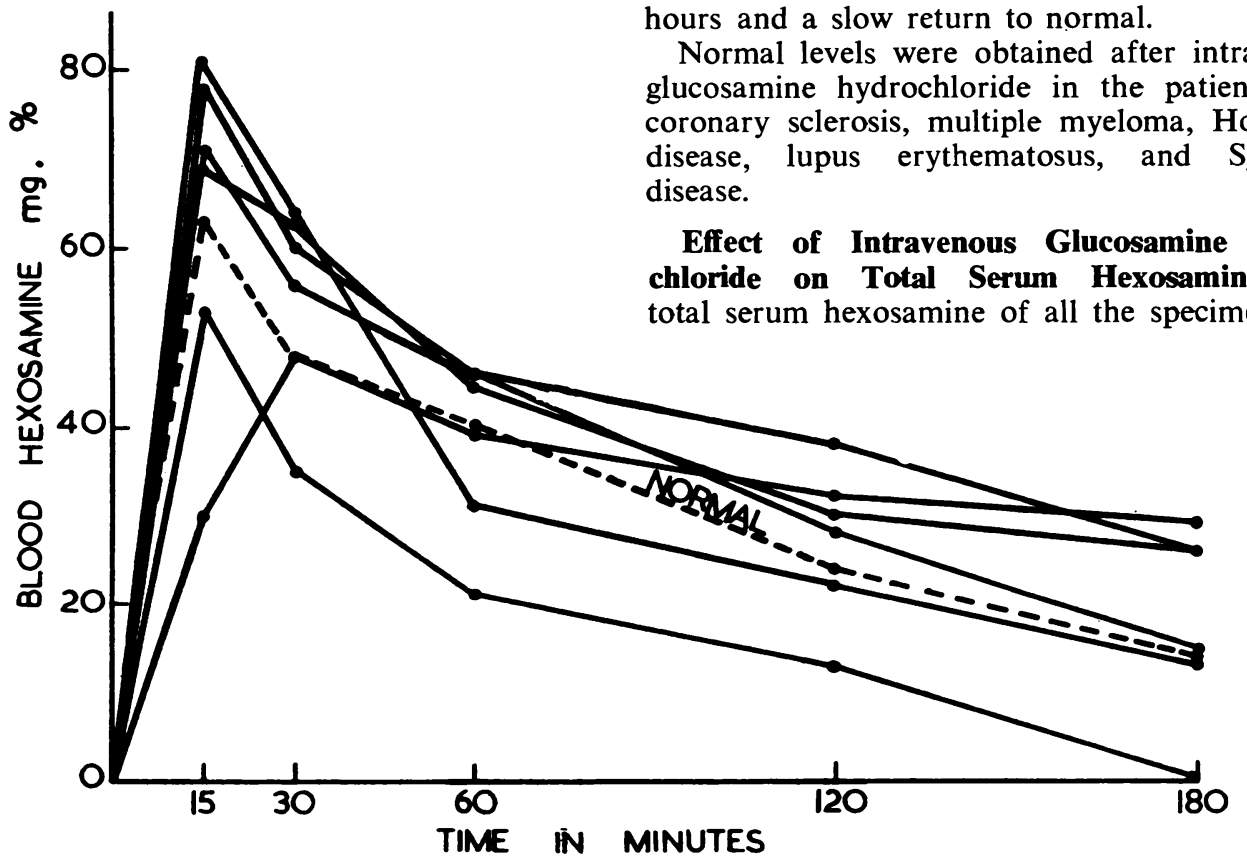

FIG. 2.-Results of the intravenous glucosamine test in the same six patients as in Fig. 1. control with insulin and diet had been inadequate in recent months. The renal function in five of these patients was normal as assessed by renal function tests and aspiration renal biopsy (Taft, Finckh, and Joske, 1954). In the remaining patient the renal function was normal and the renal biopsy showed only minimal changes, a minor degree of diffuse glomerulosclerosis and a patchy fibrous and tubular dilatation. Oral glucose tolerance tests carried out on these patients (Fig. 1) showed them to be suffering from welldefined diabetes mellitus. The glucosamine tolerance tests obtained in the same patients are given in Fig. 2 and are compared with the mean normal curve. The free blood hexosamine levels in these patients did not differ from the control group in spite of the inability of these patients to deal with a similar dose of glucose.

Seven intravenous glucosamine tolerance tests were carried out on six patients suffering from carcinoma. Results obtained were similar to those of the control group.

The group of four patients with renal disease included one with mild chronic nephritis, one with pronounced chronic nephritis, and two with a proved Kimmelstiel-Wilson syndrome consisting of diabetes mellitus, nephrotic oedema, albuminuria, and hypertension. After the injection of glucosamine hydrochloride in these patients there was a high blood hexosamine level over the three hours and a slow return to normal.

travenous

Effect of Intravenous Glucosamine Hydrochloride on Total Serum Hexosamine.-The total serum hexosamine of all the specimens was 
determined after acid hydrolysis of the serum (Weiden, 1958). All the patients investigated showed the same rise and fall as for the free hexosamine, and the rise could be accounted for by the amount of glucosamine still circulating in the blood. From this it could be concluded that during the period of the test none of the glucosamine injected had been incorporated into the serum proteins.

Excretion of Glucosamine after Intravenous Glucosamine Hydrochloride.-Nine patients were studied to determine whether all the glucosamine hydrochloride injected intravenously was excreted in the urine on the day of the test. Twenty-four-hour samples of urine were obtained where possible on the day preceding the test, on the day of the test, and on the day following. The results are given in Table II.

TABLE II

HEXOSAMINE CONTENT OF URINE OF PATIENTS IN 24 HOURS PRECEDING, DURING, AND AFTER INJECTION OF GLUCOSAMINE HYDROCHLORIDE

\begin{tabular}{|c|c|c|c|c|}
\hline \multirow{2}{*}{ Patient } & \multirow{2}{*}{$\begin{array}{c}\text { Intravenous } \\
\text { Dose } \\
\text { Glucosamine } \\
\text { (g.) }\end{array}$} & \multicolumn{3}{|c|}{ Urinary Excretion (g.) } \\
\hline & & $\begin{array}{c}\text { Before } \\
\text { 24-hour } \\
\text { Period }\end{array}$ & $\begin{array}{l}\text { During } \\
\text { 24-hour } \\
\text { Test }\end{array}$ & $\begin{array}{c}\text { After } \\
\text { 24-hour } \\
\text { Period }\end{array}$ \\
\hline $\begin{array}{l}\text { S.C. } \\
\text { G.F. } \\
\text { H.J. } \\
\text { G.F. } \\
\text { W.J. } \\
\text { B.N. } \\
\text { F.J. } \\
\text { N.J. } \\
\text { H.J. }\end{array}$ & $\begin{array}{l}14 \\
12.4 \\
16.9 \\
20.7 \\
18.2 \\
16.6 \\
14.7 \\
18.7 \\
19.7\end{array}$ & $\begin{array}{l}- \\
\overline{-} \\
0 \cdot 14 \\
0.42 \\
0 \cdot 10 \\
0 \cdot 25 \\
0 \cdot 25 \\
\overline{0} \cdot 35\end{array}$ & $\begin{array}{c}3.11 \\
5.87 \\
8.95 \\
12.4 \\
8.87 \\
8.72 \\
7.60 \\
11.0 \\
9.04\end{array}$ & $\begin{array}{l}0.21 \\
0.61 \\
0.25 \\
0.26 \\
0.26 \\
0.21 \\
0.38 \\
0.30\end{array}$ \\
\hline
\end{tabular}

Using the values obtained in the 24 hours preceding the test as a base-line, it will be seen that only a portion of the injected glucosamine is excreted and this takes place during the first 24 hours. The renal excretion then falls to the preinjection level.

After the intravenous injection of the glucosamine hydrochloride, the urine was collected as four-hourly specimens for a period of 24 hours. In most cases the free and the total glucosamine content of each sample was determined and the percentage excreted calculated. The results are given in Table III. It was found that most of the hexosamine excreted was in the free form and not combined. This suggests almost immediate excretion of the glucosamine. The excretion pattern will be discussed later.

The percentage of glucosamine excreted after an intravenous injection of glucosamine hydrochloride is fairly constant ; the mean average was 51.3 in the normal group, 58 in patients with liver disease, and 55 in patients with diabetes mellitus
TABLE III

EXCRETION OF GLUCOSAMINE AFTER INTRAVENOUS INJECTION OF GLUCOSAMINE HYDROCHLORIDE

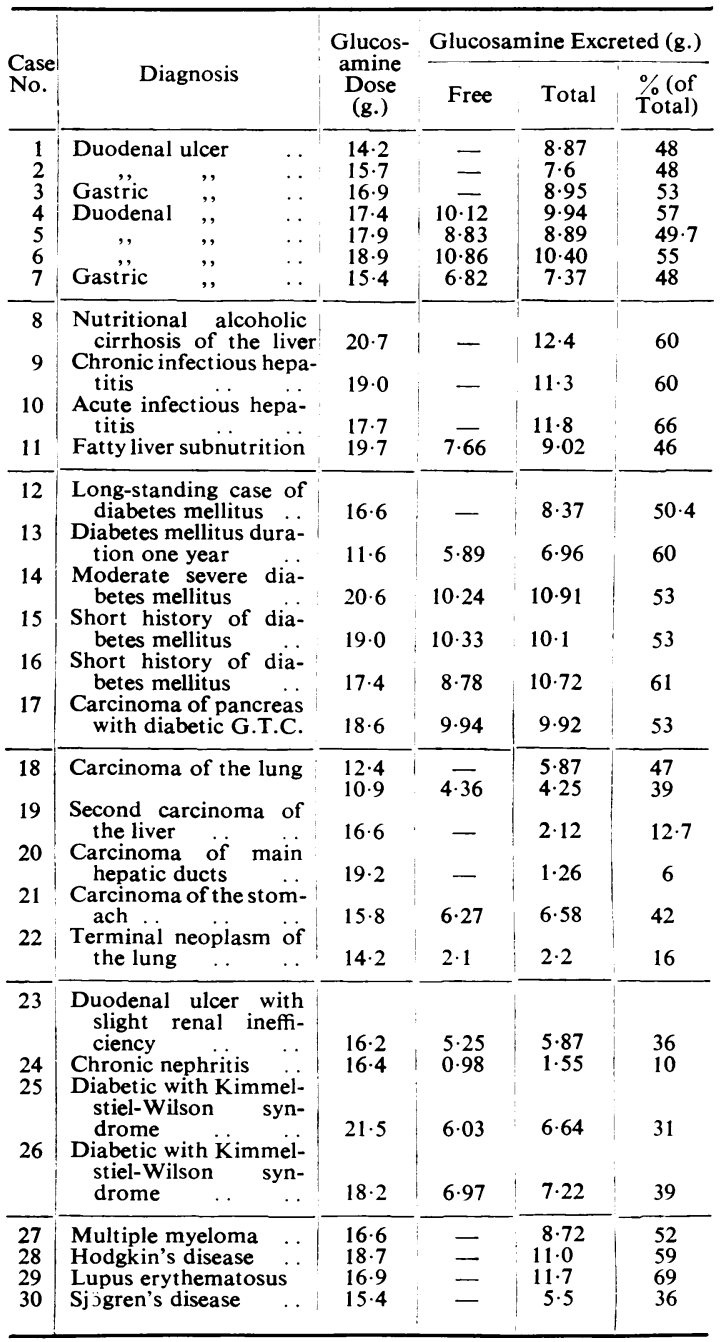

without renal disease. It was normal in the patients with multiple myeloma and Hodgkin's disease, raised in the patients with lupus erythematosus, and reduced in those with Sjögren's disease.

The presence of renal insufficiency was the main cause of reduction in the excretion of glucosamine. The patient suffering from chronic nephritis excreted only $10 \%$ and the excretion was reduced to a lesser extent in the other patients suffering from renal dysfunction. A pronounced reduction in excretion was noted in some of the patients suffering from carcinoma, and the degree of reduction appeared to depend on the degree of secondary dissemination of the carcinoma. 
The excretion pattern over the 24 hours after the injection of the glucosamine hydrochloride was determined for each patient. The greater part of the glucosamine excreted was in the first eight hours after the injection with a return to normal hexosamine level in 12 hours. A moderate reduction in excretion was seen in the patients with carcinoma and a more pronounced reduction in the patients with renal disease (Fig. 3). stomach tube was passed in two patients before an intravenous glucosamine hydrochloride test. After removing the fasting gastric contents, the glucosamine hydrochloride was injected intravenously and the entire gastric contents aspirated $30,60,90,120,150$, and 180 minutes later.

To minimize any errors which might occur due to sampling or homogenization, the entire gastric contents obtained for each time interval were

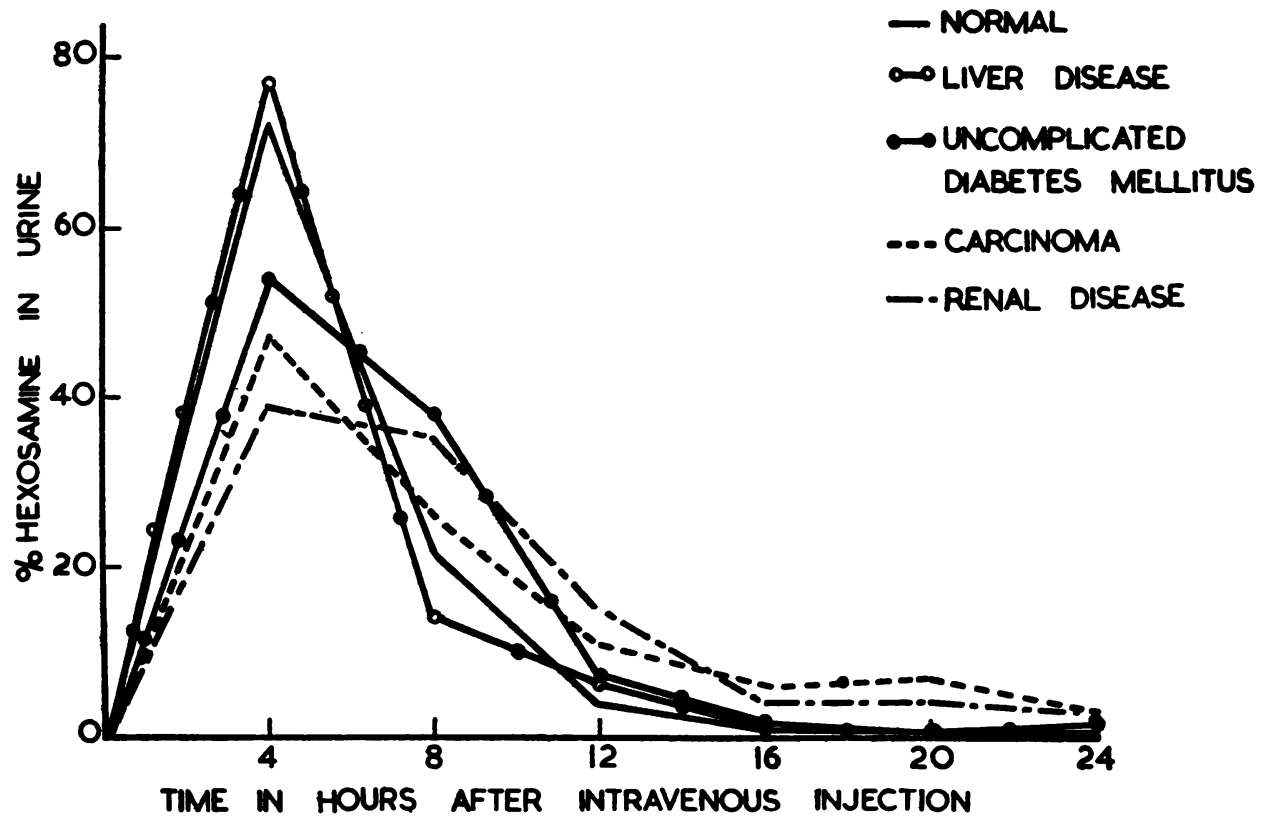

FIG. 3.-Excretion pattern of hexosamine in urine after an intravenous injection of glucosamine hydrochloride. The \% hexosamine in urine denotes the percentage of the total amount of hexosamine excreted in 24 hours.

Excretion of Glucosamine in Faeces after Intravenous Glucosamine Hydrochloride. - In one of the control patients (with quiescent duodenal ulcer), the faeces excreted during two 24hour periods after the intravenous injection of glucosamine hydrochloride were examined for hexosamine content. The entire 24-hour specimens were homogenized in a known amount of water and a sample removed for hydrolysis and hexosamine determination.

The hexosamine content of the first 24 hours was only $56.4 \mathrm{mg}$. and on the following day 47.6 mg., indicating that, in spite of the large dose $(18.2 \mathrm{~g}$.) of glucosamine hydrochloride injected intravenously, very little is excreted in the faeces. In fact the difference between the values in the two specimens cannot be considered significant.

Hexosamine Content of Gastric Juice after Injection of Glucosamine Hydrochloride.-A fine hydrolysed, neutralized, filtered, and the hexosamine content of the filtrate determined. The results are given in Table IV.

In both patients there was no significant increase in the hexosamine content of the gastric

TABLE IV

LEVELS OF HEXOSAMINE IN GASTRIC JUICE BEFORE AND AFTER INJECTION OF GLUCOSAMINE HYDROCHLORIDE

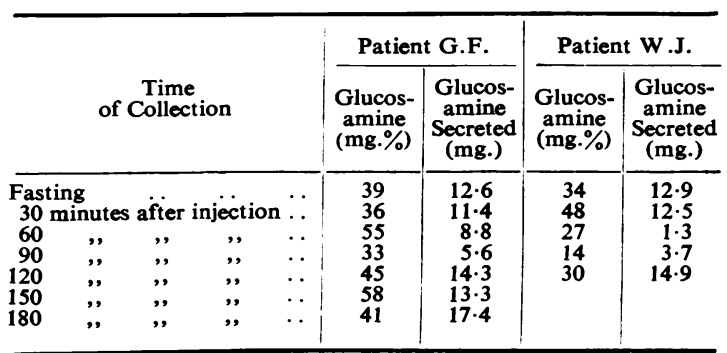


juice after an intravenous injection of $\frac{1}{3} \mathrm{~g} . / \mathrm{kg}$. body weight of glucosamine hydrochloride.

\section{Discussion}

Previous biochemical studies in man have mostly recorded the direct determination of the mucoprotein content of the serum, or the hexosamine level in the serum as an index of the mucoprotein content. Hexosamine is also a known constituent of mucopolysaccharides which compose the ground substance of connective tissue. Localization of these mucopolysaccharides has been described by Meyer (1938) and Meyer and Rapport (1951). This knowledge has mainly been acquired by their use as substrates for enzyme activity in vitro. The biosynthesis of mucopolysaccharides has been followed by the use of radioactive isotopes in bacteria (Topper and Lipton, 1953 ; Dorfman, Roseman, Moses, Ludowieg, and Mayeda, 1955) and in animals (Schiller, Mathews, Goldfaber, Ludowieg, and Dorfman, 1955).

The present paper offers a new approach to the study of hexosamine metabolism in man by following the fate of hexosamine (glucosamine hydrochloride) when injected intravenously in human controls and patients suffering from a number of diseases.

Before the intravenous injection no free hexosamine could be detected in the blood. After the injection all the patients showed a rise in the blood level and a subsequent fall within three hours. Approximately $50 \%$ of the injected glucosamine was excreted in the urine within 24 hours, most being excreted in the first eight hours.

There was no increase in the hexosamine content of the gastric juice or the faeces after the intravenous injection of glucosamine hydrochloride.

Therefore $50 \%$ of the dose was unaccounted for and can be assumed to have been taken up by the tissues. The presence of liver disease, uncomplicated diabetes mellitus, or carcinoma did not alter the findings. Results for the total serum hexosamine during the period of the test show no increase in the amount of bound hexosamine, so that it can be assumed that the injected glucosamine has not been incorporated into serum proteins. It may therefore be reasonably assumed that the remaining glucosamine is taken up by the body tissues where it is metabolized or used in the synthesis of mucosubstances.

Kawabe (1934) and Boas and Foley (1955) have shown that glucosamine injected into animals is distributed among the body tissues. Also the breakdown of glucosamine by animal tissues has been observed by Lutwak-Mann (1941), Kawakami (1934), and Watanabe (1936). Leloir and Cardini (1953) found that degradation of Dglucosamine in the cell involves phosphorylation and subsequent deamination. Bacteria (Esch. coli) have been shown to decompose D-glucosamine to form ammonia (Oka and Murachi, 1954 ; Faulkner and Quastel, 1956).

The present study revealed that in the presence of renal disease there was a delay in the return of the blood levels to normal. Also in renal disease there was a pronounced reduction in the amount of glucosamine excreted in the urine, probably due to an inability of the kidneys to excrete compounds with a free amino group as shown by the urea clearance test.

In patients with diabetes mellitus complicated by degenerative vascular disease with hypertentension, proteinuria, and renal insufficiency, the so-called Kimmelstiel-Wilson syndrome, there was a failure of the blood levels to return to normal after an intravenous injection of glucosamine hydrochloride. This was probably the result of renal insufficiency, as similar results were obtained in nephritis not associated with diabetes.

The fact that untreated patients with diabetes mellitus and no renal abnormalities were able to deal with the injected dose of glucosamine hydrochloride would seem to indicate that insulin is not necessary for its immediate distribution. Further evidence supporting this observation has been obtained and will be published later.

The present study in human subjects during health and disease provides evidence of the fate of glucosamine injected intravenously, particularly the rate of clearing from the blood stream and its excretion in the urine; the fate of the glucosamine metabolized by the tissues now awaits confirmation by isotope studies. In most respects these results obtained in human subjects parallel those previously reported for animals by Kawabe (1934), Lutwak-Mann (1941), and Boas and Foley (1955).

\section{Summary}

Glucosamine is an important component of the numerous mucocomplexes found in man, such as intercellular components, cementing substances, lubricants in joint and ocular fluids, and as aids to intestinal motility in the form of mucins of the alimentary tract.

In the present study a technique was developed for an intravenous glucosamine tolerance test, and this was carried out on 31 patients, including seven controls. 
No free hexosamine could be detected in the blood of the patients before the injection of the glucosamine hydrochloride.

After the intravenous injection of glucosamine hydrochloride in control cases there was a rise in the free blood hexosamine level followed by a return to normal in approximately three hours.

The rise in total serum hexosamine during the test would be accounted for by the free glucosamine present.

Approximately $50 \%$ of the glucosamine was excreted in the urine after an intravenous dose of glucosamine hydrochloride.

There was no increase in the hexosamine content of the gastric juice or the faeces after the intravenous injection.

Compared with the control cases there was no change in cases of liver disease, uncomplicated diabetes mellitus, multiple myeloma, Hodgkin's disease, or systemic lupus erythematosus.

In renal disease, including the KimmelstielWilson lesion of diabetes mellitus, there was a delay in the return of the blood levels to normal.

Urinary excretion in cases of widespread carcinoma and renal disease was reduced.
The distribution of that portion of the injected glucosamine which is considered to be utilized by the tissue is not known and awaits confirmation, possibly by isotope studies.

Our thanks are due to Mr. W. R. Mackay, of the Pharmacy Department of the Royal Melbourne Hospital, for preparing the intravenous solution of glucosamine hydrochloride.

\section{REFERENCES}

Boas, N. F., and Foley, J. B. (1955). Proc. Soc. exp. Biol. (N.Y.), 88,454 .

Dorfman, A., Roseman, S., Moses, F. E., Ludowieg, J., and Mayeda, M. (1955). J. biol. Chem., 212, 583.

Fabian, E. (1899). Hoppe-Seyl. Z. physiol. Chem., $27,167$.

Faulkner, P., and Quastel, J. H. (1956). Nature (Lond.), 177, 1216.

Kawabe, K. (1934). J. Biochem. (Tokyo), $20,243$.

Kawakami, I. (1934). Ibid., 20, 423.

Leloir, L. F., and Cardini, C. E. (1953). Biochim. biophys. Acta, 12, 15.

Lutwak-Mann, C. (1941). Biochem. J., 35, 610.

Meyer, K. (1938). Cold Spr. Harb. Symp. quant. Biol., 6, 91.

Meyer, and Rapport, M. M. (1951). Science, 113, 596.

Offer, T. R., and Frankel, S. (1899). Zbl. Physiol., 13, 489.

Oka, Y., and Murachi, T. (1954). J. Biochem. (Tokyo), 41, 107.

Schiller, S., Mathews, M. B., Goldfaber, L., Ludowieg, J., and Dorfman, A. (1955). J. biol. Chem., 212, 531.

Somogyi, M. (1945). Ibid., 160,69.

Stolte, K. (1908). Beitr. chem. Physiol. Path., 11, 19.

Taft, H. P., Finckh, E. S., and Joske, R. A. (1954).'Aust. Ann. Med., 3,189 .

Topper, Y. J., and Lipton, M. M. (1953). J. biol. Chem., 203, 135.

Watanabe, K. (1936). J. Biochem. (Tokyo), 23, 365.

Weiden, S. (1958). J. clin. Path., 11, 177.

Wood, I. J., Garlick, H. W., Motteram, R., Weiden, S., Moore, A., Mackay, M. A., and Turner, C. N. (1949). Med. J. Aust., 1, 541 .' 